\title{
Mathematical modeling of making mechanical engineering products based on an information model
}

\author{
Aleksey Govorkov ${ }^{1, *}$, Mariya Lavrenteva ${ }^{2}$, and Igor Fokine ${ }^{1}$ \\ ${ }^{1}$ Irkutsk National Research Technical University, 664074, Irkutsk, Russian Federation \\ ${ }^{2}$ Irkutsk Aviation College, 664025, Irkutsk, Russian Federation
}

\begin{abstract}
The paper dwells upon computer-aided mechanical engineering. We herein propose a concept of choosing operations for producing a standard airframe part based on a product image and industrial environment object classifiers. Such industrial environment objects and their inter-relations are described as a set-theoretic model.
\end{abstract}

\section{Introduction}

Any mechanical-engineering enterprise, if it is developing and launching a new product, has to do design and pre-production engineering (DE and PPE), which involves work of numerous narrowly-specialized professionals.

In modern aerospace engineering, when designing the process of making a part we need a sophisticated approach as aircraft parts have to meet specific requirements different from those in mechanical engineering.

When designing any process, the following foundations must be laid:

a) high quality has to be assured to guarantee reliable operation and long service life;

b) manufacturing time has to be minimized.

Each process is developed after this or that design is tested for manufacturability per GOST $14.201-83$.

\section{Relevance and scientific significfnce}

In modern process designs, processes are developed as documentation sets. In case of computer-aided pre-production engineering, such process desciptions are stored in a data base [1].

Operation selection is a multi-option problem. When selection operations, a number of factors are considered such as the product design and its conditions like dimensional allowances and the mutual positioning of structural elements. When choosing operations, the technologist has to optimize the sequence, to carefully set the parameters, the intermediate dimensions, removable stock, time norms, allowances, etc. This is why

\footnotetext{
*Corresponding author: govorkov as@istu.edu
} 
formalizing this stage as a part of PPE is still a relevant problem for state-of-the-art digitalenabled enterprises.

\section{Statement of problem}

The development and implementation of information technology in various industries made the concept of "digital enterprise" a sign of innovativeness that enables enterprises described that way to make highly competitive products with great consumer properties at a minimum cost. In a virtual enterprise (i.e. before a product is made), designers and technologists can take into account all the risks and analyze numerous different options to optimize the manufacturing sequence of making a semi-finished product into a finished one.

The authors hereof propose the following algorithm for designing a mechanicalengineering process based on a digital product model:

1)generate an information model (image) of your product:

a. recognize its structure

b. generate a set of structural elements (SE) with a list of important parameters

2)test the model for manufacturability

a. run quality tests

b. run quantity tests

3)design the process:

a. select the type of process;

b. select a workpiece;

c. select a set of technological bases;

d. define the sequence of forming each SE;

e. generate operations (the manufacturing sequence);

f. choose equipment;

g. choose tooling;

4)calculate part manufacturing time norms;

5)select the optimal process.

\section{Theory}

\subsection{Phase 1. Information model}

Information models are developed in accordance with the specific design and processplanning problems. Papers $[2,3,6,12]$ propose analyzing a CAD-generated digital product model as source data for defining the set of structural elements. When developing an information model, structural elements are selected based on the same source data as used for representing such elements in the digital model. Those include three basic data groups:

- geometric data of the objects contained in the digital model (DM) of a product;

- differential and integral properties of the geometric objects contained in the DM of a product;

- data on the DM object inter-relations. 


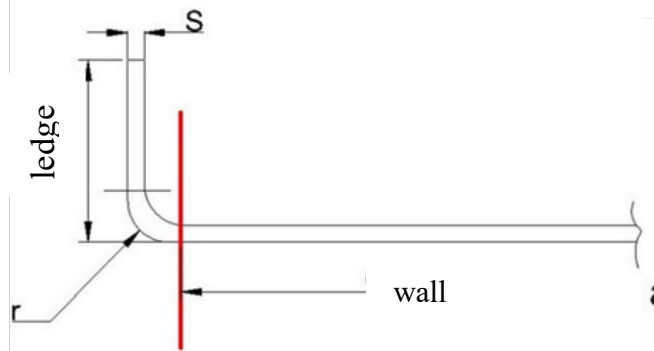

a)

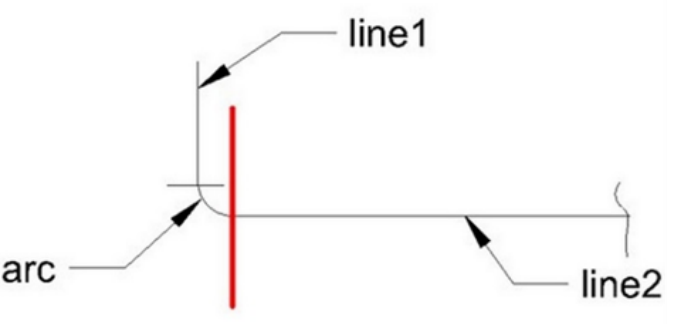

c)

(a) cross-section outline bounding the border surface; (c) basic outline (thickness ignored) divided into its component lines.

Fig. 1. Border parameters

Thus, after recognition is complete we have generated a formalized information model which can be used for semi-automatic criteria-based manufacturability testing provided there is a formalized database of technological recommendations, which testing is affected by the impact of other industrial objects.

\subsection{Phase 2. Manufacturability testing}

Papers $[5,6,7,13]$ propose comprehensive manufacturability analysis for a specific set of structural elements contained in the information model; it is suggested such analysis should be based on operation, tooling, and equipment data. This takes into account not only elements obtained by generating the elements of the entire part, but also such elements that were obtained early in design. If necessary, the set of structural elements might be altered by the designer's decision based on the manufacturability testing results [10].

\subsection{Stage 3. Generation of operations}

Consider a standard airframe part, a wall consisting of the following structural elements: billet, flanging (type 1), border, and undercutting, see Figure 2.

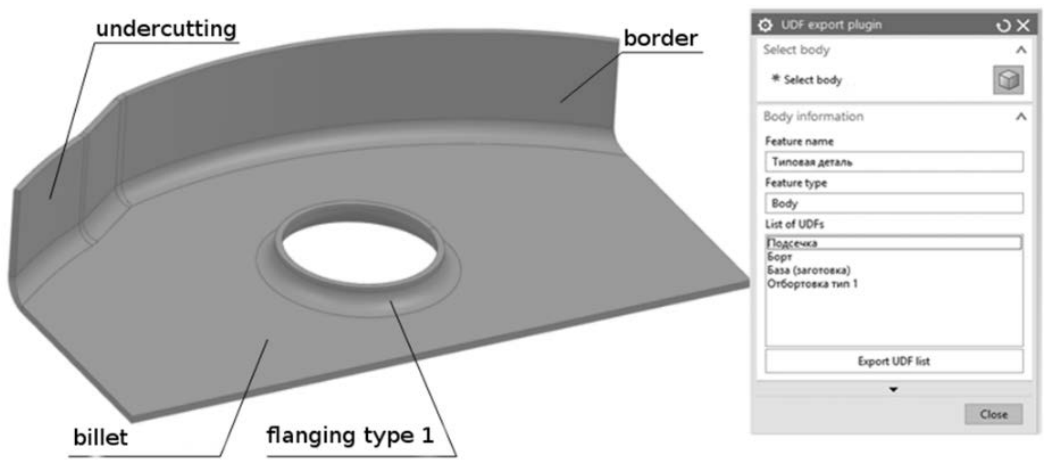

Fig. 2. The UI example and typical 3D model

First, we compile a table, see Table 1. Each line contains the name of an SE and its manufacturing options. The manufacturing sequence, the presence of superficial interrelations with other SE, and other factors are thereby taken into account. In this case, operations are limited to the known methods of manufacturing this specific SE. 
Table 1. SE manufacturing operations

\begin{tabular}{|l|l|l|l|l|c|}
\hline \multirow{2}{*}{\multicolumn{1}{|c|}{ Name }} & \multicolumn{5}{c|}{ Operation options $j=1 \ldots n(m)$} \\
\cline { 2 - 7 } & \multicolumn{1}{|c|}{1} & 2 & $\ldots$ & $n$ & $m$ \\
\hline Billet $\left(\mathrm{SE}_{1}\right)$ & $\mathrm{O}_{1}$ & $\mathrm{O}_{j+1}$ & $\ldots$ & $\mathrm{O}_{n}$ & - \\
\hline Flanging $\left(\mathrm{SE}_{2}\right)$ & $\mathrm{O}_{l}$ & $\mathrm{O}_{j+1}$ & $\ldots$ & $\mathrm{O}_{m-1}$ & $\mathrm{O}_{m}$ \\
\hline Border $\left(\mathrm{SE}_{3}\right)$ & $\mathrm{O}_{l}$ & - & - & - & - \\
\hline Undercutting $\left(\mathrm{SE}_{4}\right)$ & $\mathrm{O}_{l}$ & $\mathrm{O}_{j+1}$ & - & - & - \\
\hline
\end{tabular}

To sample operations for each SE each operation must bear an ID code. To that end we propose using the encodings of the Russian Classifier of Mechanical Engineering and Instrumentation Operations.

From the perspective of the knowledge theory, the designing process can be attributed to the recognition of an object in a space of the entire set of objects. In this case, we recognize not something that actually exists but something that has to exist for our purposes. In this formulation, designing consists of the following components:

1) $\mathrm{C}=\left\{\mathrm{c}_{i}\right\}, i=\overrightarrow{1, n}$ is the set of process design goals;

2) $\mathrm{P}=\left\{\mathrm{p}_{i}\right\}, i=\overrightarrow{1, m}$ is the set of process parameters;

3) $\mathrm{X}=\left\{\mathrm{x}_{i}\right\}, i=\overrightarrow{1, k}$ is the set of possible solutions;

4) $\mathrm{V}=\left\{\mathrm{v}_{i}\right\}, i=\overrightarrow{1, l}$ is the set of process solutions.

The components of the designing process are interrelated. There is a correspondence between the set of goals and the set of parameters, as well as between the set of parameters and the set of solution options. If for our design we choose a subset $\mathrm{C}_{c}$ in the set $\mathrm{C}$, then we compose correspondences in the set $\mathrm{X}$ to find the subset $\mathrm{X}_{\mathrm{c}}$ comprising the image of the set $\mathrm{C}_{c}$. Mapping $\mathrm{X}_{\mathrm{c}}$ onto the set of estimates enables us to find an optimized-forgoals solution.

In the structure of an enterprise, we can identify the following sets of similar parameters, presented in a hierarchic order. The top level includes the sets of such parameters, the structure of which is shown in Figure 3 as it exists in the industrial environment. Fundamental is the set of product specific solution parameters $\left(\mathrm{D}_{\mathrm{TP}}\right)$. It includes four subsets without common elements:

- product parameters as a part of the solution, $\mathrm{D}_{\mathrm{P}} \in \mathrm{D}_{\mathrm{TP}}$;

- operation $\mathrm{D}_{\mathrm{TO}}$ parameters as a part of the solution $\mathrm{D}_{\mathrm{TO}} \in \mathrm{D}_{\mathrm{TP}}, \mathrm{D}_{\mathrm{TO}} \cap \mathrm{D}_{\mathrm{P}}=\emptyset$;

- tooling $\mathrm{D}_{\text {Сто }}$ parameters as a part of the solution $\mathrm{D}_{\text {Сто }} \in \mathrm{D}_{\text {TР }}, \mathrm{D}_{\text {Сто }} \cap \mathrm{D}_{\mathrm{P}}=\emptyset$, $\mathrm{D}_{\text {Сто }} \cap$ $\mathrm{D}_{\mathrm{TO}}=\emptyset$;

other parameters of the solution $\mathrm{D}_{\Pi \mathrm{P}}$, not included in the subsets a $\mathrm{D}_{\mathrm{p}}, \mathrm{D}_{\text {TO }}$ and $\mathrm{D}_{\text {СТО }}$, so that $\mathrm{D}_{\Pi \mathrm{P}} \in \mathrm{D}_{\mathrm{TP}}, \mathrm{D}_{\Pi \mathrm{P}} \cap \mathrm{D}_{\mathrm{P}}=\emptyset, \mathrm{D}_{\Pi \mathrm{P}} \cap \mathrm{D}_{\mathrm{TO}}=\emptyset, \mathrm{D}_{\Pi \mathrm{P}} \cap \mathrm{D}_{\mathrm{CTO}}=\emptyset$.

Therefore, the set of all parameters of a product solution is the merger of five mutually disjoint sets:

$$
\mathrm{D}_{\mathrm{TP}}=\mathrm{D}_{\mathrm{P}} \cup \mathrm{D}_{\mathrm{TO}} \cup \mathrm{D}_{\text {СТо }} \cup \mathrm{D}_{\mathrm{O}} \cup \mathrm{D}_{\text {ПР }}
$$

In the set $\mathrm{D}_{\mathrm{P}}$ of product parameters, identify the subset $\mathrm{D}_{\mathrm{K}}$ of the parameters of such structural elements that the product consists of. Note that $D_{К \ni} \in D_{P}$. Besides, when designing a solution for making a product, we add the set of equipment parameters $D_{0}$ so 
that $\mathrm{D}_{\mathrm{O}} \cap \mathrm{D}_{\mathrm{TP}}=\emptyset$. However, when selecting and analyzing the objects of a solution, what matters is not just the set $\mathrm{D}_{0}$, but also the subset $\mathrm{D}_{\text {Отех }}$ of significant technological parameters of the equipment, which is defined as follows:

$$
\mathrm{D}_{\text {Отех }} \in \mathrm{D}_{\mathrm{O}} \cap \mathrm{D}_{\mathrm{TP}}=\varnothing \text {. }
$$

In the set $\mathrm{D}_{\mathrm{TO}}$, specify the subset $\mathrm{D}_{\text {Топ }}$ of transition parameters paired to at least one parameter of an equipment element. Note that $\mathrm{D}_{\text {ТОп }} \in \mathrm{D}_{\text {ТО }}$, and the sets $\mathrm{D}_{\text {Кэ }}$ and $\mathrm{D}_{\text {ТОп }}$ may or may not have common elements, which depends on the design of the product as well as on the set $\mathrm{D}_{\mathrm{O} \text { тех }}$.

Formally, the process can be represented as a simplified set of the elements of the structural model, where each element has a specific function and is structurally, functionally, and information-wise related to other elements.

The high dimensionality of design problems in case of complicated systems and objects makes it advisable to use a block-hierarchy approach, where the designing process is divided into inter-related hierarchical levels.

With that approach, a process can be described mathematically as the function $\Phi$ that demonstrates the reshaping of the machined part $\mathrm{S}$. The entire shaping process can be shown as a transition from the workpiece state $S_{0}$ to the finished-part state $S_{K}$, which is achieved by a specific sequence of operations.

\subsection{Phase 3.f Equipment selection}

Equipment is selected specifically for each operation. This problem is soluble based on operation type data, manufacturing precision, the standard process of choice, and the dimensions of the part to be made.

\section{Conclusions}

The paper proposes a model for designing a process for image-based manufacturing of products associated with NX models. When generating the manufacturing sequence, one has to find the optimal operations and the sequence in which the part's structural elements should be made. These problems are soluble by analyzing the structure of a 3D model, the interrelations between its SE with due account of all design and technology-related pecularities; such analysis generates the image of the product. This image enables one to design a sketch-based manufacturing proccess (sequence) when creating and linking a CAD model in NX.

The desire to automate the initial design stages results in the development of expert systems capable of creating solutions with the skill of a qualified designer/technologist working in the field.

\section{References}

1. A.A. Kabanov, Object model for the analysis of aircraft products with account of inheritance for the assessment and control of the efficiency of manufacturing systems in discrete mechanical engineering at the stage of their organizational and engineering design or modernization. Kazan: Scientific and Technical Bulletin of the Volga Region, pp. 161-168, (2014)

2. A.A. Mitin, Use of production rules to display the integrity limits in graphical CAM editors. Proceedings of the Oryol State Technical University. Series: Information 
Systems and Technology. Oryol: Oryol State Technical University, pp.173-177, (2008)

3. A.K. Shmakov, V.V. Mironenko, K.K. Kirishina, A. S. Stanislavchik, V.V. Kotov, Effect of the average velocity of the free part of the semifinished product on the process of pneumothermal forming in the superplastic regime. Metallurgist, v. 57. Issue 1-2. pp. 8-12. (2013)

4. E.V. Zenkov, L.B. Tsvik Formation of divergent testing efforts and experimental evaluation of material strength under biaxial stretching // PNRPU Mechanics Bulletin,. No. 4. pp. 110-120, (2015)

5. E.V. Zenkov, L.B. Tsvik Stress-Strain State of Prismatic Samples with Hollow Chamfers // Russian Engineering Research. v. 33, No. 10. - pp. 562-565, (2013)

6. G.Kh. Irzaev, Expert methods for controlling the manufacturability of industrial products: a monograph. Moscow: Infra-Inzheneriya, , pp 192. (2010)

7. G.Kh. Irzaev, Research and modeling data streams of design and engineering adjustments in the development and medium-batch manufacturing of products. Organizator proizvodstva.. v. 52. Issue 1. pp. 131-135.(2012)

8. K.A. Odnocurtcev, Laboratory equipment for automated control of assembly tooling components. Bulletin of Irkutsk State Technical University. Issue 12 (59). pp. 41-47. (2011)

9. P.E. Chimitov, Generating the image of a product for designing the airframe assembly process. Reshetnyov's Readings: Proceedings of the XII International Scientific Conference in the Memory of the Designer General of Rocket Space Systems, Academician M. F. Reshetnyov, pp.183-184. (2008)

10. P.M. Krastyaninov, R.M. Khusainov, Selection of equipment for machining processing of parts using NX and Teamcenter programs. (012041), IOP Conf. Series: Materials Science and Engineering, v.134, (2016)

11. R.M. Khusainov, I.F. Sharafutdinov, Methods of assessing the dynamic stability of the cutting process using Unigraphics NX. (012042), IOP Conf. Series: Materials Science and Engineering, v.134, (2016)

12. S.A. Aksenov, E.N. Chumachenko, A.V. Kolesnikov, S.A. Osipov, Determination Of Optimal Conditions For Gas Forming Of Aluminum Sheets. Procedia Engineering 11 th. pp. 1017-1022. (2014)

13. S.A. Aksenov, I.Y. Zakhariev, A.V. Kolesnikov, S.A. Osipov, Characterization of superplastic materials by results of free bulging tests. Materials Science Forum. v. 838-839. pp. 552-556. (2016)

14. V.A. Grechishnikov, R.M. Khusainov, D.R. Akhkiyamov, S.Y. Yurasov, O.I. Yurasova. Identifying the primary rigidity axes in the elastic system of a metal-cutting machine. Russian Engineering Research, , v. 36, No. 8, pp. 673-676, (2016)

15. V.E. Gozbenko, S.K. Kargapoltsev, D.N. Kornilov, N.V. Minaev, A.I. Karlina, Definition of the main coordinates of the car with two-level spring suspension. International Journal of Applied Engineering Research. v. 11. Issue 20. pp. 1036710373. (2016) 